\title{
Internet y los sueños de una renovación democrática $* 1$
}

\author{
LANGDON WINNER \\ Rensselaer Polytechnic Institute, Troy, N. Y.
}

Resumen. A lo largo de la historia del desarrollo tecnológico en los Estados Unidos, se ha constatado la creencia persistente en que existe una relación entre el avance de la tecnología y un tipo de ideal político, a saber, la convicción de que los nuevos artefactos técnicos revitalizarán la sociedad democrática al aumentar la participación ciudadana y la calidad de esta participación, dotando a los ciudadanos de nuevos y más extendidos recursos políticos y económicos que los capacitan para el autogobierno. En la época actual, esta creencia histórica se aplica al ámbito de los ordenadores y las redes telemáticas, como Internet. Sin embargo, cabe preguntarse si el solo aumento de recursos técnicos entre la población tiene una contrapartida real en cuanto la participación democrática en asuntos políticos, o más bien se trata solamente de una extendida creencia idealista sin fundamento constatado.
ABSTRACT. Along the history of the technological development in the United States, a belief has been identified about the relationship between the advance of technology and a type of political ideal, namely, the conviction that new technical devices will revitalize democratic society, increasing civic participation and its quality, by endowing citizens with new and more extended political and economic resources that qualify them for selfgovernment. Nowadays, this historical belief is applied to the domain of computers and the telematic networks, such as Internet. However, it is necessary to wonder whether the simple increase of technical resources among the population has a real counterpart in relation to the democratic participation in political matters or it is only an extended idealistic belief without verified foundation.

Un asunto vivo y muy persistente en el pensamiento político americano es la convicción de que las nuevas tecnologías revitalizarán la sociedad democrática, capacitando a los ciudadanos para obtener los recursos políticos y económicos necesarios para autogobernarse de modo efectivo. Sentimientos de este tipo han reaparecido en cada generación desde principios del siglo XIX, siendo un tema estándar de la retórica pública nacional. La cons-

* Traducción de Verónica Sanz González.

${ }^{1}$ Este texto de Langdon Winner forma parte de un libro en el que intervienen varios autores y cuyo título es The civic web: online politics and democratic values, ed. de David M. Anderson y Michael Cornfield, Oxford, UK, Rowman \& Littlefield Publishers, 2003. El texto de Winner «The Internet and Dreams of Democratic Renewal» figura como capítulo 11. 
trucción de canales, vías ferroviarias, fábricas y plantas de energía eléctrica, así como la introducción del telégrafo, el teléfono, el automóvil, la radio y la televisión, han estado siempre acompañados de entusiastas proclamas sobre cómo cada innovación proporcionaría a la gente corriente mayor acceso a los recursos, mayor poder sobre decisiones clave, y amplias oportunidades para la participación política. Con la llegada de los ordenadores personales e Internet a finales del siglo XX, esta persistente visión se ha reavivado poderosamente. Muchos observadores han predicho que un tipo radical de democracia - descentralizada, antijerárquica y de participación directa - fluiría seguramente del extendido uso de los aparatos electrónicos digitales. ¿Están bien fundadas estas expectativas de renovación política?

\section{Ecos históricos}

La creencia en este tipo de conexión entre tecnología y democracia está presente en los principales trabajos de ingeniería de los primeros años de los Estados Unidos. El canal de Erie, por ejemplo, se anunciaba no sólo como el canal que llevaría cargamentos de este a oeste, sino también como la mismísima apoteosis del ciudadano común. En el acto de apertura del canal en 1825, el Utica Sentinel declaraba que el proyecto era especialmente relevante como «prueba que será presentada a toda la humanidad de las capacidades del pueblo libre, cuyas energías, no dirigidas por ninguna autoridad absoluta y con una suma que sería insuficiente para costear la pompa real de cualquier monarquía durante un solo año, han llevado a cabo un trabajo de mayor utilidad pública que el que las fuerzas reunidas de todas las monarquías del mundo hayan efectuado desde su fundación en la tierra» ${ }^{2}$. La fecha elegida para la gran ceremonia de apertura de muchos importantes proyectos tecnológicos de este período - el gran ferrocarril de Pennsylvania (1826), el ferrocarril entre Baltimore y Ohio (1828), el canal Baltimore-Ohio (1828), el ferrocarril entre Boston y Worcester (1835), y otros - fue el Día de la Independencia. Las celebraciones de los nuevos sistemas técnicos el día 4 de julio los asocia de forma indiscutible con las tradiciones democráticas emergentes en el país.

La fuerte asociación establecida entre el progreso técnico y la vitalidad de la ciudadanía continuó a lo largo del siglo XIX. Una revista de negocios de 1841 elogiaba la «navegación a vapor» y otros inventos, por el modo en que éstos elevaban las capacidades políticas de los pueblos corrientes: «En exacta proporción a la extensión de la libertad política y la difusión de la inteligencia popular, se ha producido el avance de la invención y los artefactos útiles... Así como el poder político ha sido difundido entre grandes ma-

2 «The Grand Canal Celebration», Utica Sentinel, 8 de noviembre de 1824, citado por David E. Nye, American Technological Sublime, Cambridge, Mass., MIT Press, 1994, p. 36. 
sas de hombres, la mente humana ha sido dirigida hacia aquellas invenciones que se diseñan para otorgar sólidos beneficios a esas masas» ${ }^{3}$. Las proclamas sobre el progreso tecnológico durante este período enfatizan comúnmente la contribución que estos progresos hacen a la igualdad política, la competencia cívica y a la ampliación de los horizontes de la participación democrática. En 1836, George S. White, un defensor incondicional de la industrialización, alababa las continuas mejoras técnicas describiéndolas como «una máquina moral, la cual, en la misma proporción en que facilita la comunicación rápida y constante entre todas las partes de nuestra nación, tiende efectivamente a perfeccionar la civilización, y a elevar el carácter moral de su gente» 4 .

A lo largo de las décadas, la admiración por la técnica se ha ido desplazando de cada nuevo aparato al siguiente. A principios del siglo $\mathrm{xx}$, por ejemplo, las expectativas que hoy tenemos respecto de los ordenadores e Internet se atribuían a la radio. En 1924, Herbert Hoover, entonces secretario de comercio, elogiaba la radio por su potencial político: «No nos olvidemos de que el valor principal de este gran sistema no descansa primariamente en su alcance, ni siquiera en su eficiencia... Por primera vez en la historia de la humanidad tenemos la capacidad de comunicarnos simultáneamente con millones de compañeros nuestros, para proporcionarles entretenimiento, instrucción, y una amplia visión de los problemas y los eventos nacionales» ${ }^{5}$. Para algunos entusiastas de la radio de este período, la inmediatez de las transmisiones radiofónicas era el presagio de la participación ciudadana en la política, por los fuertes vínculos que proporcionaba entre los representantes elegidos y el pueblo. En un número de la revista Radio Broadcast de 1924, el columnista Mark Sullivan se preguntaba: «¿Permitirá la radio el gobierno del pueblo?», y respondía con un convencido «Sí». «En la actualidad», escribía, «el público es dependiente de la censura delegada en la persona del reportero periodístico... El mérito fundamental de la radio en el congreso será que permitirá al público acceder directamente a la información» 6 .

Las encomiendas de este tipo no estuvieron limitadas a los aparatos de comunicación. El avión, el automóvil, los plásticos, los electrodomésticos y las grandes presas y sistemas del agua fueron ampliamente elogiados y considerados como manifestaciones de un espíritu populista en expansión ${ }^{7}$. Por ello, a David E. Lilienthal, presidente de la Autoridad del Valle de Ten-

3 «American Steam Navigation», Hunt's Merchant Magazine, febrero de 1841, p. 14, citado en Nye, p. 38.

${ }_{4}$ George S. White, Memoir of Samuel Slater, Philadelphia, 1836, reimpreso en The New England Mill Village, 1790-1860, ed. de G. Kulik et al., Cambridge, Mass., MIT Press, 1982, p. 355.

5 Citado en Todd Lapin, «Daja Vu All Over Again», Wired, 3.05, febrero de 1995, p. 175.

${ }^{6}$ Citado en Lapin, p. 218.

7 Véase, por ejemplo, Joseph Corn, The Winged Gospel: America's Romance with Aviation, 1900-1950, Nueva York, Oxford University Press, 1983. 
neesse, le costó enormes esfuerzos convencer de que el TVA - un voluminoso complejo de alrededor de cincuenta presas, plantas eléctricas y cauces artificiales para el control de desbordamientos comenzado en 1933- no produciría una molesta concentración de poder o de control centralizado. Su libro, TVA: Democracy on the March, argumentaba que el sistema TVA era un gran encuentro popular entre los americanos de a pie y las fuerzas de la naturaleza. «Cuando se siguen los principios que se encuentran en las raíces de la democracia», escribía, «la electricidad, así como los minerales de la tierra, proveen al hombre del estímulo para su propia vida, al igual que una oportunidad para trabajar junto a otros hombres para conseguir un propósito mayor que cualquier propósito individual. A través de un acto de unión de los esfuerzos de la participación ciudadana se refuerza la esencial libertad humana, y aumentan sus satisfacciones» ${ }^{8}$.

Las proclamas de revitalización cívica a través de la innovación tecnológica tienen un elemento de verdad. Claramente, los avances acumulativos en la producción industrial, el transporte y las comunicaciones han mejorado la calidad de vida de los ciudadanos comunes. Es razonable concluir que, a través del desarrollo de los mecanismos de comunicación electrónica, la gente estará mejor educada e informada sobre el mundo social y político. Los americanos han sacado partido de los instrumentos de producción y comunicación disponibles que pueden mejorar los intereses personales y de grupo. Actualmente una gran cantidad de tecnologías son elementos clave dentro del tejido de la sociedad política americana; de hecho, es prácticamente imposible imaginar la democracia moderna sin su parafernalia de dispositivos técnicos.

Durante los dos siglos pasados, no obstante, la retórica elogiadora de cada nuevo matrimonio entre tecnología y democracia ha tendido también a ignorar algunos hechos importantes, y ha descuidado amplios patrones de desarrollo sociotécnico, entre los que se incluyen algunos que proyectan sombras sobre esas esperanzas de mayor igualdad, participación y ciudadanía democrática efectiva. Por tanto, aunque los ferrocarriles fueran alabados como el medio de transporte que ayudaría a democratizar los Estados Unidos y haría el continente más accesible a una gran masa de población, en las últimas décadas del siglo XIX los trenes se convirtieron en el foco de las protestas populares de los granjeros y los habitantes de poblaciones pequeñas, que veían sus vidas controladas por los bancos centralizados y las líneas ferroviarias. De igual modo, las primeras expectativas de que el sistema de fábricas llegara a ser la joya de la corona del país fueron pronto ensombrecidas por décadas de luchas laborales por los salarios, los horarios de trabajo, los beneficios y, en general, por las condiciones de trabajo en las cadenas de montaje. A pesar de que las fábricas manufactureras contribuyeron a la

8 David E. Lilienthal, TVA: Democracy on the March, twentieth anniversary ed., Nueva York, Harper \& Row Publishers, 1953, p. 91. 
mejora de las vidas de la población trabajadora, también fueron ampliamente consideradas como un lugar de reglamentación estricta, de desigualdad y de relaciones sociales de opresión.

De la misma manera, el romance democrático con el automóvil (que continúa en gran medida aún entre nosotros) debe ser también visto dentro del escenario de un drama político y social más amplio. Durante las décadas centrales del siglo XX, la construcción de grandes autopistas y carreteras de circunvalación produjo una vía de escape a través de la cual principalmente los blancos de clase media de los suburbios abandonaron las ciudades industriales, dejando tras sí los grupos menos favorecidos. Considerado dentro del sistema completo del uso de la tierra, las hipotecas y la planificación del tráfico, el automóvil se convirtió en un elemento de división económica, política y social que perturba la democracia americana hasta nuestros días.

En resumen, una serie de problemas han complicado las esperanzas de igualdad política, inclusión, poder compartido y amplia participación de una población más cultivada por el uso creciente de sistemas tecnológicos. Las visiones estáticas de la «tecnodemocracia» han fallado históricamente en su renuencia a reconocer las complejas circunstancias sociales, organizativas y políticas en las que las tecnologías estaban inmersas. No obstante, la recurrencia de malformaciones y desórdenes relacionados con la tecnología nunca han acallado los sueños de renovación. Tan pronto como un nuevo mecanismo tecnológico aparece en escena, todas las historias y problemas del pasado son simplemente olvidadas, y reemplazadas por una confianza renovada en que la sociedad ha tropezado por fin con algo maravilloso y sin precedentes.

\section{La esperanza renacida}

Durante las últimas décadas del siglo xx, el lugar predilecto donde localizar la salvación política dentro del reino de los instrumentos se trasladó a la tecnología electrónica y digital. Cuando las comunicaciones por ordenador se extendieron desde las organizaciones militares y corporativas a la sociedad, sus partidarios proclamaron que a los ciudadanos les había sido entregado un maravilloso regalo, una herramienta que restauraría el poder del autogobierno a la gente corriente. Predicciones de esta índole eran centrales en el bestseller de Alvin Toffler (1981), The Third Wave, donde los ordenadores y «la casita de la electrónica» eran considerados la nueva primavera de la política popular ${ }^{9}$. Los escritos sobre la sociedad de la información durante la década de los ochenta daban optimistas proyecciones de despliegue de la «revolución informática», especialmente de los efectos radicalmente demo-

9 Alvin Toffler, The Third Wave, Nueva York, Morrow, 1980. Traducción al español en Ed. Orbis, Barcelona. 
cratizadores del ordenador personal. A partir de ahora la gente corriente contaría con el poder que ofrecen los ordenadores para competir con el que tienen las grandes organizaciones ${ }^{10}$.

A principios de los noventa, sin embargo, el foco de las esperanzas políticas se trasladó del ordenador personal (PC) a las redes de ordenadores (Internet) y su potencial para dar poder a los ciudadanos. Una de las primeras y más conocidas declaraciones de esta promesa fue el libro The virtual Community, de Howard Rheingold (1993). Cuidadoso en presentar su utopía como una posibilidad atrayente más que como un futuro necesario, la visión de Rheingold se hacía eco de las clásicas esperanzas que tenían las generaciones precedentes acerca de la tecnología y la política. «El significado político de [la comunicación mediada por los ordenadores] descansa en su capacidad para desafiar el monopolio que la clase política tiene sobre los poderosos medios de comunicación, y quizás, por tanto, revitalizar la democracia-basada-en-los-ciudadanos». Basándose en sus observaciones de los foros de discusión en Internet, Rheingold predecía una «red mundial de comunicación centrada en, y controlada por, los ciudadanos», un «ágora electrónica» que estaba al alcance de nuestra mano ${ }^{11}$.

Al final de la década, esas esperanzas eran si cabe más vivas, y se continuaban anunciando como si fuera un descubrimiento totalmente nuevo. En este sentido, Andrew Shapiro en The Control Revolution lamenta que la evolución de la moderna democracia liberal representativa haya abandonado las elecciones políticas decisivas en manos de los representantes públicos elegidos. Shapiro dice: «Ahora, sin embargo, la tecnología puede permitirnos realizar muchas de esas decisiones por nosotros mismos. Podemos convertirnos no sólo en ciudadanos, sino en ciudadanos-gobernantes, jugando cada uno de nosotros un rol a la hora de organizar la distribución de los recursos, el manejo del poder estatal y la protección de los derechos» ${ }^{12}$.

Expresiones de este tipo han llegado a ser moneda de cambio en las descripciones que se hacen de Internet en los medios periodísticos, así como en cientos de foros de discusión on line. La experiencia de muchos usuarios de los ordenadores les induce a creer que el mundo está siendo rápidamente democratizado por la enorme cobertura de la red, y que ha aumentado su propia influencia sobre las decisiones. La sensación de que aumenta el poder

${ }^{10}$ Véase mi discusión sobre este período en «Mythinformation», en mi libro The Whale and the Reactor: A Search for Limits in an Age of Hight Technology, Chicago, University of Chicago Press, 1986, pp. 97-117. Traducción al español, La ballena y el reactor: una búsqueda de los límites de la alta tecnología, Barcelona, Gedisa, 1987.

${ }^{11}$ Howard Rheingold, The virtual Community: Homesteading on the Electronic Frontier, Reading, Mass., Addison-Wesley, 1993, p. 14. Traducción al español, La comunidad virtual: una sociedad sin fronteras, Barcelona, Gedisa, 1996.

${ }^{12}$ Andrew Shapiro, The Control Revolution: How the Internet Is Putting Individuals in Charge and Changing the World We Know, Nueva York, Public Affairs, 1999, p. 154. 
a través de la implicación personal en el ciberespacio está actualmente muy extendida y es muy fuerte.

La buena noticia quizá sea que la predicha revitalización de la esfera pública vía Internet indudablemente amplificará docenas de revoluciones tecno-democráticas previas, muchas de las cuales, como hemos visto, han ido haciendo de la política americana una famosa utopía de condiciones ideales de igualdad económica, de poder compartido sobre las decisiones, y de elevación de los niveles de participación política. Una tradición sin precedentes de aumento del poder ciudadano directo. No obstante, frente a estas felices visiones de éxito, uno debe pararse a plantear algunas cuestiones serias: ¿Está teniendo lugar realmente una revolución democrática? ¿Existe, por ejemplo, una nivelación del influjo político, una disminución de la concentración del poder político y económico en manos de unos pocos? ¿Qué hemos de hacer con la pretensión de que Internet ayuda a generar una nueva forma de democracia vital y efectiva?

Por ahora está claro que Internet es un nuevo medio de comunicación enormemente popular. Los americanos parecen estar ansiosos por subir a bordo de este nuevo medio: usar el correo electrónico, entrar en los foros de discusión y navegar por los billones de páginas de la World Wide Web. Estudios realizados por la Radio Pública Nacional y el Centro de Comunicación de la Universidad de California en Los Ángeles (UCLA) indican que aproximadamente dos terceras partes de los adultos en los Estados Unidos usan Internet, o al menos lo han hecho en una ocasión ${ }^{13}$. Aunque continúan existiendo desigualdades significativas en cuanto al acceso a Internet, esas diferencias parecen irse estrechando en los Estados Unidos, ya que el uso del ordenador se está instalando en la vida diaria en todos los niveles económicos.

Algunos estudios sobre usuarios de Internet indican también que, para aquellos con capacidad de registrarse en la red, existen a menudo fuertes sentimientos de felicidad por el uso del correo electrónico y los navegadores, por tener acceso a vastas fuentes de información, noticias y entretenimiento, así como por las oportunidades de hablar con mucha más gente y de extender la esfera de sus contactos. Parece que la impresión más común es que hemos sobrepasado los confines de las comunicaciones electrónicas que han caracterizado durante largo tiempo los medios audiovisuales de comunicación. Uno ya no está sujeto a que los mensajes se transmitan desde una o muy pocas fuentes. El toque de dedo de una sola persona proporciona un universo virtualmente ilimitado de información. Por esta razón, mucha gente que usa este medio experimenta una sensación de liberación, siendo cons-

13 NPR, Fundación Kaiser y Kennedy School of Goverment, Technology Survey, //npr.org/programs/specials/poll/technology/, febrero de 2000; UCLA Center for Communication Policy, Surveying the Digital Future: The UCLA Internet Report, www.ccp.ucla.edu, noviembre de 2000 . 
cientes de que, de algún modo, ellos pueden controlar el tipo de conexión que tienen con las noticias y la información, lo cual incluye fuentes que no están filtradas (o al menos poco filtradas) por editores, programadores de noticias y otros árbitros de la «información aceptable».

En esta misma línea, mucha gente disfruta de relaciones organizativas que parecen menos abrumadas por la jerarquía, y libres de la autoridad y de las estructuras sociales que antes servían de intermediarios dentro del flujo de información, bienes y servicios. Muchos entusiastas de Internet creen que la eliminación de capas organizativas que se ha dado en el presente dentro de algunas innovadoras empresas comerciales globales se extenderá de modo inevitable a las relaciones políticas en su conjunto. En su amplio texto, Declaración de independencia del ciberespacio, John Perry Barlow avisa a «los gobiernos del Mundo Industrial» de su persistente irrelevancia. «Yo declaro que espacio social global que estamos construyendo es naturalmente independiente de cualquier tiranía que queráis imponernos. Vosotros no tenéis ningún derecho moral a regularnos, ni tampoco poseéis ningún método de aplicación del que nosotros tengamos auténticos motivos para temer» ${ }^{14}$.

Igualmente importante para muchos entusiastas de Internet es la posibilidad de que la gente corriente pueda convertirse en productora, y no meramente consumidora, de la información electrónica diseminada por la red. Como todo el mundo puede escribir mensajes, crear páginas web, abrir un boletín de noticias, iniciar contactos y organizar grupos de interés on line, las posibilidades de que exista una ciudadanía que se exprese y delibere parecen enormes. A este respecto, la atracción que causa el mundo virtual llega a ser positivamente seductora. Recientemente, la estudiosa feminista Ellen Balka realizó una retrospectiva sobre las tendencias que el pensamiento feminista ha tenido respecto a la relación entre tecnología y sociedad. Ella pone de manifiesto que durante la pasada década ha habido un relevante declive en la frecuencia y calidad de las contribuciones feministas a este debate. «iAdónde - se pregunta - han ido todas las críticas feministas a las tecnologías de la información? Nosotras hemos ido por el ciberespacio allá donde la tecnología ha hecho posible que vayamos, y en nuestro entusiasmo por la tecnología hemos perdido la perspectiva feminista crítica.» En la visión de Balka, la implicación con Internet está reemplazando rápidamente otro tipo de compromiso político más directo, cara a cara ${ }^{15}$.

Si miramos hacia la esfera de la política convencional - campañas electorales, actividades de quienes pertenecen a los grupos de presión, intentos de conformación de la opinión pública - está claro que Internet es actualmente un medio para movilizar los intereses políticos de un modo rápido y

14 John Perry Barlow, A Declaration of the Independece of Cyberspace, www.eff.org/pub/Publications/John_Perry_Barlow/barlow_0296.declaration, 9 de febrero de 1996.

${ }^{15}$ Ellen Balka, «Where Have All the Feminist Technology Critics Gone?», Loka Alert, 6:6, 11 de noviembre de 1999, www.loka.org/alerts/loka.6.6.txt. 
sencillo. Como se explica a lo largo de este libro ${ }^{16}$, grupos e individuos de todo el espectro ideológico están usando las páginas web, las listas de servidores y el correo electrónico para organizar y hacer públicos sus puntos de vista. El carácter global de la red hace que todo esto sea muy atractivo, porque Internet no sólo ofrece la posibilidad de una diseminación más amplia de los mensajes individuales de cada uno, sino que también hace más difícil el control por una agencia exterior. Por ejemplo, los grupos neonazis y otros grupos racistas, que en Alemania están sujetos a grandes restricciones, están moviendo sus páginas web a servidores estadounidenses, esquivando así el poder político de su país sobre su propaganda. Aunque el flujo digital global de ideas políticas ha aumentado las esperanzas de que se produzca una mayor comprensión y respeto entre los diferentes grupos raciales, no hay ninguna garantía de que esto ocurra.

De nuevo, como muestra este libro ${ }^{17}$, las campañas electorales de todos los niveles tienen en la actualidad una o varias páginas web donde presentan las posturas de los candidatos. Además, una nueva característica bastante discutible es que los grupos opositores de un candidato pueden producir de un modo muy barato sátiras atractivas que parecen reales. Durante la campaña presidencial del año 2000, tanto George W. Bush como Albert Gore fueron llevados de aquí para allá por cientos de web sites que llevaban su nombre y sus fotos, donde se ofrecían cómicos comunicados de prensa ficticios y «declaraciones políticas». La página www.GWBush.com, por ejemplo, defendía la amnistía presidencial general para toda persona que permaneciera en la cárcel por la indiscreción juvenil de poseer drogas ${ }^{18}$. El rápido aumento del uso de Internet como un vehículo para transmitir bromas es uno de los desarrollos más sorprendentes en Internet en los años recientes. El que esto pueda ser considerado como una contribución positiva al discurso público o simplemente como otra expresión más del mal humor ciudadano es algo que aún no está claro.

Se pueden ofrecer infinidad de ejemplos que apoyan la conclusión de que Internet está haciendo importantes contribuciones a la democracia. Pero ¿cómo deben de ser sopesadas estas declaraciones dentro de una comprensión más amplia de la política actual?

\section{Comprobando la realidad}

Puede haber poca duda de que Internet ya se ha convertido en una característica importante de la cultura política contemporánea. Los ordenadores en red ofrecen la oportunidad para que se produzcan modos de expresión vivos

\footnotetext{
16 Véase nota 1.

17 Ibid.

18 Véase la página web www.GWBush.com.
} 
y diversos. A este respecto se parece enormemente a otros dominios de la cultura popular - entretenimiento, deportes, moda y consumismo, entre las más importantes - que han jugado un rol democratizador en la sociedad moderna. Los bienes de consumo, por ejemplo, se han convertido en medios a través de los cuales la gente se expresa a sí misma: lo que compran, lo que visten, lo que poseen y lo que usan es un símbolo de sus vidas. El mercado responde a estas expresiones del gusto y el deseo popular y a las identidades que la gente prefiere, intentando producir más de eso mismo a través de la publicidad. Las películas de Hollywood y los programas de televisión, de modo similar, reflejan la cultura democrática proporcionando un espejo a las fantasías de las audiencias masivas. Se puede catalogar directamente una porción sustancial de la organización y el contenido de la comunicación actual en Internet en una misma categoría: una contribución a la cultura de los símbolos, mensajes y significados ampliamente compartidos, pero también altamente comercializados, de la sociedad actual.

Pero ¿puede considerarse que estas manifestaciones culturales de la democracia son una contribución a la democracia en un sentido político más básico? ¿La movilización de la atención y la actividad general hacia Internet es efectiva cuando se trata de cuestiones de poder y política? ¿Mejora la Red la cantidad y calidad de la participación ciudadana?

Preguntándonos cuestiones de este tipo, nos damos cuenta de que no podemos considerar que Internet - como otras tantas tecnologías anunciadas en el pasado - no es una entidad que existe por sí misma, aislada de otras prácticas y organizaciones políticas. Los entusiastas de la democracia de Internet esgrimen a menudo argumentos del tipo de los siguientes: «Por un lado observamos los patrones dominantes de la política corriente: la política de la diplomacia, los partidos políticos, etc., que se usan para ser el centro del poder. Por otro lado, en el lado de Internet, hay patrones completamente nuevos de redes de ordenadores, en los cuales se desvanecen las jerarquías, nadie ostenta el poder, y se crean nuevas expresiones de ciudadanía.» Estos argumentos parecen apelar, según nos parece entender, a dos esferas que ocupan claramente el mismo espacio político. Si las actividades de la comunicación on line no modifican sustancialmente los patrones de influencia sobre decisiones políticas clave, haciendo que la influencia sea más ampliamente compartida que antes, entonces los anuncios de que se está produciendo una revolución democrática son bastante prematuros.

Por supuesto, lo que ocurra a largo plazo con estos desarrollos no se anticipa con fiabilidad. Esta interpenetración entre Internet y la sociedad política sigue inmersa en un proceso, cuyo desenlace es altamente incierto. ¿Quién sabe cómo será nuestra política dentro de veinte años? Pero no obstante, uno puede tomar nota de los patrones que hay hoy día, los cuales nos sugieren que la continuidad más que la ruptura será la característica del influjo de las estructuras y prácticas telemáticas en la política y la configuración del poder social. 
Tomemos la afluencia de votantes, por ejemplo. Internet parece haber tenido hasta ahora un efecto mínimo en el número de gente que va de hecho a las urnas. En los Estados Unidos, la participación en las votaciones está normalmente en un 50 por 100 o menos ${ }^{19}$. Contando la gente que no se registra para votar, esto significa que aproximadamente un 25 por 100 de la población se convierte realmente en mayoría efectiva, en fuerza gobernante. El rango de votantes en la mayoría de las elecciones - típicamente hombres y mujeres de clase media, preocupados por los impuestos, la educación y la seguridad social - constituyen un sector aún menor de la población, pero reciben una atención desproporcionada por parte de los candidatos. Estas tendencias en las elecciones americanas son preocupantes, y dan lugar a una gran cantidad de cinismo. Generan una sensación de amargo desdén hacia la política por parte de la ciudadanía, que los políticos hábiles saben manipular a su favor. Hasta ahora, Internet no ha hecho nada para cambiar ni la escasez de participación en las votaciones, ni para explotarse políticamente a sí misma.

¿Qué podemos decir sobre la extendida sugerencia de que la gente está encontrando nuevos foros para la discusión pública y la actividad ciudadana en Internet, foros centrados en intereses, cuestiones y campañas concretas? Hay algo que decir sobre esta interpretación de Internet, como se ejemplifica en el capítulo $10^{20}$. No obstante, si nos limitamos simplemente al volumen de participación, no parece que se haya dado ningún aumento durante la era de Internet en comparación con la era de la televisión o la del periódico. De hecho, los estudios de Robert Putnam sobre la cultura cívica muestran un firme descenso de la participación ciudadana en la vida pública desde la Segunda Guerra Mundial ${ }^{21}$. El número de gente que está dispuesta a comprometerse en las actividades públicas, más allá de pagar sus impuestos y obedecer las leyes, está disminuyendo. Por supuesto, sigue persistiendo una minoría, aunque muy visible y vociferante, que encuentra en Internet la gracia divina. Pero si la democracia significa algo, significa una amplia participación de la gente corriente en los asuntos relacionados con el gobierno del país. La tendencia hacia una mayor participación no parece ser especialmente esperanzadora, a menos que se

19 Un análisis reciente de la situación se encuentra en Mark Lawrence Kornbluh, Why America Stopped Voting: The Decline of Democracy and the Emergence of Modern American Politics, Nueva York, New York University Press, 2000.

${ }^{20}$ Véase nota 1.

${ }^{21}$ Robert D. Putnam, Bowling Alone: The Collapse and Revival of American Community, Nueva York, Simon and Schusster, 2000. En un artículo anterior, Putnam investiga varias posibles causas del declive de la participación comunitaria durante la última mitad del siglo Xx. Escribe: «He descubierto que sólo hay un sospechoso contra quien se acumula la evidencia circunstancial, y en este caso se vuelve una evidencia incriminatoria y que directamente muestra que... la culpable es la televisión.» Véase «Tuning In, Tuning Out: The Strange Disappearance of Social Capital in america», PS: Political Science \& Politics, vol. XXVIII, núm. 4, diciembre de 1995, p. 677. 
considere que la extendida apatía es un signo de que la gente está básicamente satisfecha ${ }^{22}$.

¿Y qué hay de la idea de que la democracia está experimentando un renacimiento, dado el ímpetu de la discusión política, el debate y la recolección de información? Los primeros informes no son especialmente prometedores. El ideal del discurso democrático de la antigua polis griega o de los decimonónicos mítines cívicos de Nueva Inglaterra, y que se aplauden en los escritos de John Dewey y Jurgen Habermas, sugiere que la gente con distintos compromisos y puntos de vista pueden discutir, argumentar, deliberar y, por último, decidir juntos el rumbo de una acción. En las verdaderas situaciones democráticas, lo que sostiene la promesa final de un buen gobierno es la diversidad de los participantes, así como su compromiso de colaborar con personas cuyas ideas difieren de las suyas.

Además, como observa Galtson en el capítulo $3{ }^{23}$, los foros abiertos y diversos no son tan característicos de la participación en Internet. La gente normalmente «personaliza» las fuentes de información que les interesa, seleccionando, por ejemplo, sólo las reseñas o noticias sobre un asunto en particular o sobre su equipo deportivo favorito. Internet hace posible una selección mucho mayor de la que permitían los periódicos tradicionales; en las décadas anteriores, la prensa presentaba a los lectores los asuntos de forma rutinaria con un repertorio de temas bastante amplio, debido a que los editores tenían que dirigirse a un extenso dominio de lectores potenciales. Hoy en día, los usuarios pueden delimitar aquella serie de asuntos que se centran justamente en lo que les interesa en un momento dado.

El mismo tipo de selección se puede encontrar en los grupos de chat y en las listas de servidores de Internet. Gente que piensa de manera similar comparte información e ideas, reforzando opiniones que ya sostenían previamente. En Internet, así como en los escenarios políticos cara a cara, la gente normalmente se encuentra incómoda con la ambigüedad, el desacuerdo y las expresiones de puntos de vista distintos al suyo. En los encuentros cara a cara, no obstante, existe a veces un momento en el que la gente siente la necesidad de unirse y buscar un compromiso. De hecho, éste es uno de los grandes premios de la comunicación política en democracia: el deseo de expresar lo que uno piensa, de escuchar los puntos de vista de lo otros, y buscar después un terreno común. Desgraciadamente, muchos de los actuales foros en la Red carecen de esta cualidad. La mayoría de las veces, lo que se encuentra es gente con similares puntos de vista hablando entre ellos. Cuando emergen voces disidentes o puntos de vista diferentes, se dan a menudo con la aspereza y la crítica que es característica de algunas discusiones on line: los internautas permanecen en la discusión el tiempo suficiente

${ }^{22}$ Para una interesante discusión véase Nina Eliashop, Avoiding Politics: How Americas Produce Apathy in Everyday Life, Nueva York, Cambridge University Press, 1998.

${ }_{23}$ Véase nota 1. 
para repartir unos cuantos «disparos» y después desaparecer - un lujo que Internet permite - . Por comparación, las comunidades situadas geográficamente tienden a hacer sus críticas de manera más responsable; uno tiene que levantarse al día siguiente y mirar a sus vecinos a la cara. Por tanto, Internet parece ser bastante mejor para encenderse airadamente o desahogarse que para buscar soluciones democráticas.

Los científicos políticos no deben sorprenderse de descubrir que las discusiones deliberativas no se forman en la red. Numerosos estudios resaltan que el aumento de la cantidad de información o del número de canales accesibles a los ciudadanos no implica ninguna mejora ni en la voluntad de participar en política ni en la calidad de la participación cuando esta tiene lugar ${ }^{24}$. La idea de que el acceso a enormes recursos de información almacenada electrónicamente hará a los ciudadanos más efectivos y sabios no es siempre verdad. Debe ocurrir algo más, dentro del espacio de comunicación, para que una democracia activa y efectiva salga a la luz.

Ese elemento extra, en mi opinión, incluye un compromiso directo y mantenido con otros en comunidades de interés para cada individuo, sobre cuestiones que afectan a la vida de todos. Durante muchas décadas el sistema de partidos políticos en América satisfizo esta condición en cierto modo, aunque de una manera que no era completamente democrática. La gente corriente traía una preocupación al líder del partido político local, el cual organizaba las fuerzas del partido y prestaba cierta atención a las necesidades de la gente de su distrito. Este representante comunicaría esas necesidades a los líderes del partido de niveles más altos, los cuales en las siguientes legislaturas cumplirían con lo pactado, lo cual proporciona una respuesta, aunque sea parcial, a las preocupaciones de la gente corriente.

A la luz de esto, Internet se parece mucho a la televisión en cuanto a que sirve como sustituto del contacto directo entre los ciudadanos y los líderes políticos, que anteriormente tenía lugar en los partidos políticos. Aunque Internet es en algunos aspectos más interactiva que la televisión en cuanto a lo que la política se refiere, ambos medios comparten una fuerte tendencia a desconectar la vida diaria y las necesidades más inmediatas del pueblo llano de los procesos políticos. La mayoría de los ciudadanos carecen de cualquier contacto directo con personas que están directamente involucradas en la política o en los gobiernos. La inmensa mayoría sencillamente no están comprometidos de ningún modo con los asuntos públicos más importantes de la actualidad, y ni si quiera hablan con personas que sí lo están.

Todo esto significa que Internet ha hecho muy poco hasta ahora con respecto al modo fundamental en que se gobierna la sociedad. Los patrones de

${ }^{24}$ Véase, por ejemplo, Sidney Verba y Norma Nie, Participation in America: Political Democracy and Social Equality, Nueva York, Harper and Row, 1972, y Philip E. Converse, «Change in the American Electorate» en The Human Meaning of Social Change, ed. de Angus Campbell y Philip Converse, Nueva York, Sage, 1972, pp. 263-337. 
poder económico profundamente enraizado que han prevalecido a lo largo del tiempo en los Estados declarados democráticos continúan siendo prominentes y efectivos. Las élites basadas en los sectores financieros y empresariales influyen fuertemente en la elección de los candidatos, conforman las ideas de los partidos políticos, financian las campañas electorales y, finalmente, controlan los resultados de la acción política del gobierno. La ausencia continuada de compromiso ciudadano es la condición subyacente que permite que florezca el ejercicio del poder oligárquico contemporáneo, quedando la democracia reducida a un conjunto de eslóganes cada vez más huecos.

\section{¿Comunicaciones para quién?}

Una cuestión importante a la que deberán de hacer frente las políticas democráticas en las próximas décadas es la de si los modos de comunicación disponibles en Internet se convertirán (como sugieren los entusiastas) en una alternativa a los actuales patrones que relacionan los medios de comunicación electrónicos con las concentraciones de poder político - condición que debilita mucho la democracia contemporánea-. El crecimiento a nivel mundial de los oligopolios en la publicidad y en los medios de comunicación electrónicos limita severamente la variedad de la información, las noticias y la expresión pública disponible en periódicos, revistas, libros, películas y programas de televisión con que se encuentra la mayoría de los ciudadanos ${ }^{25}$. Según las grandes compañías trasladen sus operaciones a Internet ofreciendo atractivos «paquetes» de diversión mediática, se puede eclipsar la acariciada experiencia de Internet como un lugar de expresión libre. La esfera de las redes de ordenadores y la comunicación sin cable ha sido declarada como «el próximo gran mercado»: una zona empresarial que las compañías globales esperan dominar.

Existe ahora, por ejemplo, un enorme interés por dirigir a los internautas a través de portales, páginas que organizan la amplia gama de información en Internet en rutas predeterminadas y altamente comercializadas, al estilo de la estructura de canales de la televisión por cable o vía satélite. No es sorprendente que los propietarios de muchos de los portales de Internet sean las mismas compañías que controlan también la televisión americana. Los portales transmiten cada vez más la impresión de que en Internet se encuentra todo lo que puede existir sobre ocio, deportes, compras, actuaciones, planes de vacaciones y otras variedades de consumo. Llama la atención que en ellos casi no existan categorías y vínculos que animen a las personas que navegan habitualmente a explorar aún el más convencional de los asuntos

${ }^{25}$ Robert W. McChesney, Rich Media, poor Democracy. Communication Politics in Dubious Times, Urbana, III: University of Illinois Press, 1999. 
políticos. La misma sensibilidad política subyacente se encuentra en los canales por cable o vía satélite que se dedican a Internet - Tech TV, por ejemplo - cuyas ofertas, las veinticuatro horas del día, acentúan la visión de las comunicaciones digitales como un adictivo bombardeo de oportunidades para comprar, jugar a videojuegos, y gastar dinero en general. Al contrario de lo que esperaban los visionarios de Internet, ninguno de los programas de esos canales tech resalta las oportunidades de los ciudadanos de comprometerse con los problemas públicos. Lo que sugieren en cambio es que el sillón-ball y el ratón-ball son «deportes» muy parecidos.

Hasta el momento, los intentos de cambiar Internet dentro de este modelo ideal corporativo no han sido completamente satisfactorios. Se podría esperar que el número y la diversidad de posibilidades de las comunicaciones en Internet favorezcan finalmente la democracia popular. Pero compañías como Time Warner/AOL, Yahoo!, el imperio mediático Rupert Murdoch, Disney/ABC, MSNB y otras compañías globales están trabajando duro para conformar el flujo de la información electrónica y obtener los beneficios que resultarán de este nuevo medio. Guiar las ideas, expectativas y preferencias que flotan en las mentes de los políticos y los ciudadanos dentro de este dominio es el principal objetivo que persiguen estos programas organizados de manipulación política y social en Internet. Una resistencia organizada contra esta influencia está lejos de ser evidente.

Un problema muy cercano a éste, que afecta también a la democracia, es la flagrante corrupción de los políticos, los candidatos y los representantes públicos cuando se trata de conseguir fondos para sus campañas publicitarias televisivas. Como la tendencia actual se dirige hacia la total fusión de Internet y televisión en un futuro no muy lejano, parece probable que las prácticas más lamentables de recaudación de fondos se transfieran sin más al nuevo medio del ciberespacio. Las redes de ordenadores podrían convertirse fácilmente en recursos con los que personas adineradas y diferentes organizaciones compren el acceso y el poder, y fijen en la agenda asuntos que afectan al modo de vida de la gente. Los entusiastas de la democracia en Internet no han tenido en cuenta estas posibilidades, especialmente la intensa comercialización del ciberespacio y la probable transferencia de las patologías existentes en la política actual al nuevo medio. Se decantan, en cambio, por las fantasías de la vieja y raída utopía sobre tecnología y democracia que siempre reaparece en la historia americana, aunque en el pasado no haya demostrado ser una buena guía para la acción. Complacerse en estos ensueños utópicos mientras ignoramos alternativas políticas importantes -como, por ejemplo, las políticas de telecomunicaciones tomadas a mediados de los noventa - es lo que equivocadamente se denomina «ser optimistas sobre el futuro». 


\section{Conclusión}

Considerando el asunto dentro de la política general de las comunicaciones, el principal problema que se nos plantea es menos el de las peculiaridades de cada medio de comunicación concreto, que el asunto del control de los canales de todo tipo (especialmente el tipo de reglas que gobiernan el acceso, la exclusión de ellas y su uso). En los Estados Unidos viene siendo común un determinado desarrollo de los medios de comunicación, de modo que en un principio parecen conectados enormemente con nociones como el bien público, pero posteriormente acaban sirviendo para siempre a los intereses económicos privados. Una vez tras otra, el país dona enormes cantidades de dinero proveniente de los impuestos a la investigación y el desarrollo de los medios electrónicos, esperando que la población en su conjunto se beneficie de ellos. Pero según un modelo repetido durante décadas, el gobierno se desentiende pronto del asunto, entregando los nuevos medios de comunicación a empresas que buscan sus propios beneficios. A lo largo de las décadas, quienes han gestionado la política pública americana siempre han estado dispuestos a abandonar la apuesta pública en manos de las compañías (y ahora Internet), porque creen que el sector empresarial conoce mejor cómo construir y administrar los medios de comunicación sociales.

Esta absoluta necedad de regalar la enorme riqueza pública que suponen los recursos electrónicos es ya suficientemente dañina. Pero, además, a este mal se le suman otros efectos negativos que esta política genera, como limitar las posibilidades del acceso libre y general a los nuevos medios de comunicación en el ámbito de las artes, la educación y otros ámbitos de carácter público. No nos debe sorprender, por tanto, que una sociedad que durante tantos años ha visto sistemáticamente maniatada la capacidad de sus ciudadanos de utilizar ellos mismos las herramientas del discurso electrónico se despierte en la actualidad encontrándose con una esfera pública marchita y deformada, y con un creciente cinismo en la población. No es probable que la receta utópica — «añadir Internet y revolver»- cambie la situación.

Una cuestión clave es, entonces, si nuestra sociedad tiene de facto la voluntad y el compromiso necesarios para preservar un amplio dominio cultural, un dominio donde se limite el influjo de la publicidad y otras fuerzas del mercado y donde se fomenten las actividades culturales. Un consenso que preserve un espacio electrónico público de este tipo, que nunca fue muy fuerte en los Estados Unidos, se ha esfumado totalmente durante las eras Reagan/Bush y la era Clinton, donde se ha considerado que el mercado global es el único árbitro de las prioridades sociales. Internet, tal y como existe hoy en día, muestra extraordinariamente bien esta tendencia. De lo que damos testimonio en nuestro país no es de la revitalización de la política 
democrática, sino de la creación de una nueva y enorme esfera de desarrollo de la empresa comercial.

Como muestran claramente los titulares y las páginas de las publicaciones financieras, Internet está mudando rápidamente hacia una nueva etapa. La televisión, tal y como ha existido en el siglo pasado, está abriendo paso a un nuevo híbrido, que incluye televisión de alta definición, una red de ordenadores mundialmente conectados y un patrón de competentes formatos digitales. Los enormes conglomerados de empresas mediáticas saben exactamente lo que quieren conseguir con esta transformación: unos beneficios sin precedentes en esta esfera sin reglas que combina el teléfono local y el de larga distancia, la televisión por cable y los servicios lucrativos en Internet. Entonces, ¿qué pueden demandar los ciudadanos de las sociedades democráticas - si es que demandan algo- de este nuevo medio digital? ¿Qué pueden pedir que sea distinto de lo que se ofrece actualmente: más deportes, más películas, más oportunidades de consumo? Es ésta una cuestión enormemente importante, que está esperando atención y un estudio y debate más extensos. 